\title{
O078: 6 years of national German hand hygiene campaign-where do we come from and where are we heading to?
}

\author{
C Reichardt", M Behnke, K Bunte-Schönberger, P Gastmeier, "AKTION Saubere Hände" \\ From 2nd International Conference on Prevention and Infection Control (ICPIC 2013) \\ Geneva, Switzerland. 25-28 June 2013
}

\section{Introduction}

The national German hand hygiene $(\mathrm{HH})$ campaign "AKTION Saubere Hände" started at January $1^{\text {st }} 2008$. The campaign is based on the WHO "Clean Care is Safer Care" campaign and is funded for six years be the German ministry of health. By March 2013, over 1300 health care institutions are actively participating.

\section{Objectives}

We present data on the development of observed compliance rates, alcohol based hand rub consumption (AHC) and hand rub dispenser availability over the campaign period.

\section{Methods}

All participants have to implement a multimodal intervention program. Among other parameters, they have to collect the following data: AHC, hand rub dispenser availability and on a voluntary basis observed compliance data. All three parameters are collected using a defined data collection tool. Observers are trained by the campaign team members. AHC is given unit based yearly in ml per patient day. Hand rub availability is defined as one dispenser per ICU bed and per two nonICU beds. The definition of $\mathrm{HH}$ opportunities (HHO) is based on the WHO Model "My 5 moments of hand hygiene". Observations were done before intervention and after interventions. A minimum of 200 observations per unit was defined.

\section{Results}

There are 1300 health care institutions participating in the campaign by March 2013. Among those are 815 hospitals
(45\% of all hospitals in Germany), 66 rehabilitation clinics, 242 long term care facilities and 183 outpatient care facilities. There was an increase of AHC of 47,5\% $(\mathrm{p}<0,001)$ in 166 hospitals that provided AHC data consecutively from 2007 to 2011 . Hand rub dispenser availability increased to over $90 \%$ in non-ICU's and to over $100 \%$ in ICU's $(\mathrm{p}<0,001)$. Compliance increased from $64 \%$ before to $74 \%$ after one intervention in 82 hospitals with 249 units (136205 HHO's) $(\mathrm{P}<0,001) .6$ hospitals with 25 units have observed over four periods. Observed $\mathrm{HH}$ compliance increased from $60 \%$ at baseline to $71,2 \%$ after four observation periods $(\mathrm{p}<0,001)$.

\section{Conclusion}

Hospitals participating in the campaign have to implement a multimodal intervention program. The increase of AHC and observed compliance show, that the multimodal intervention program based on the WHO strategy led to improved $\mathrm{HH}$ compliance.

\section{Disclosure of interest}

None declared.

Published: 20 June 2013

Institute of Hygiene, Universitiy Medicine Berlin, Charite, Berlin, Germany

doi:10.1186/2047-2994-2-S1-078

Cite this article as: Reichardt et al: 0078: 6 years of national German hand hygiene campaign-where do we come from and where are we heading to? Antimicrobial Resistance and Infection Control 2013 2(Suppl 1): O78.

\section{C) Biomed Central}

(c) 2013 Reichardt et al; licensee BioMed Central Ltd. This is an Open Access article distributed under the terms of the Creative Commons Attribution License (http://creativecommons.org/licenses/by/2.0), which permits unrestricted use, distribution, and reproduction in any medium, provided the original work is properly cited. 